\title{
Experimental Investigation, Modeling and Optimization of Circularity, Cylindricity and Surface Roughness in Drilling of PMMA Using ANN and ANOVA
}

\author{
FLORIN SUSAC* FELICIA STAN
}

, Dunarea de Jos University of Galati, Center of Excellence Polymer Processing, 47 Domneasca Str., 800008, Galati, Romania

Abstract. In this paper, experimental investigation, modeling and optimization of the drilling of PMMA are performed using the Taguchi Design of Experiments (DOE), analysis of variance (ANOVA) and artificial neural networks (ANN) methods. Drilling experiments were conducted on PMMA to assess the impact of process parameters (drill diameter, spindle speed, and feed rate) on the hole-quality characteristics (surface roughness, circularity error, and cylindricity error). ANOVA was performed to identify the drilling parameters that have a statistically significant influence on the hole-quality characteristics. A predictive model for the hole-quality characteristics was derived using a four-layer ANN with a backpropagation algorithm and a sigmoidal transfer function at the hidden layers. The ANN model was able to accurately predict the hole-quality parameters with the absolute mean relative errors of the testing data in the limits of 3 to $7 \%$. Based on the experimental results and analytical modeling, it was found that drilling of PMMA requires lower spindle speed and high feed rate when the integrity of the drill hole is the main quality criterion.

Keywords: Drilling, ANOVA, ANN, Surface roughness, PMMA

\section{Introduction}

Machining of thermoplastic polymers (turning, milling, drilling or others) is a complex process affected by various machining factors such as cutting parameters, geometry and material of the cutting tool, and thermo-mechanical properties of the machined polymers [1-12]. Thus, designers and engineers have to deal with great challenges when machining thermoplastic materials because the cutting parameters have a significant influence on the machinability attributes like surface integrity and finish $[3,4,7,8,13]$, cutting forces $[1,11,14,15]$ tool wear and life [14] and dimensional and geometric accuracy $[2,9,10,15,16]$. On the other hand, there is an overlap between the machining factors. Therefore, to optimize the machining processes, it is necessary not only to identify the most influencing cutting parameters on the machinability attributes, but also to develop analytical and numerical models for prediction, control and optimization of the machining processes $[2,3,7,12,15]$.

Optimization of the cutting parameters is an important step in machining of polymers and polymerbased composites and, therefore, many researchers have employed different methods, e.g. Taguchi method, analysis of variance [17], artificial neural networks, response surface methodology or combination of these methods, to identify the process parameters that have a significant effect on the surface roughness [4-7,10-14] and derive the predictive models for various output parameters such as surface roughness $[2-5,7,8,18]$, cutting forces $[1,11,14,15]$ or delamination factor $[1,10,11,14]$.

Among them, artificial neural networks (ANN), in the last years, were employed as the main methodology for modeling and optimization of both input and output parameters of the cutting process [3,19-22]. The ANNs are able to learn by example and do not need to know the theory behind a phenomenon. Moreover, the ANN methods are useful to model phenomena for which the relationships between the inputs and outputs are non-linear.

*email: florin.susac@ugal.ro 
Literature reported a significant number of studies that have investigated the capability of ANN methods to determine the optimum cutting conditions and derive reliable models for prediction of the hole quality of composites $[4,7,9,12,16]$. However, there is a gap with respect to the optimization of hole quality characteristics for unfilled polymers.

Polymethylmethacrylate (PMMA) is an amorphous thermoplastic polymer that can easily replace polycarbonate at a lower cost, depending on application purpose. PMMA is a transparent material having good mechanical and optical properties. Although PMMA has a large applicability, including medicine and industry, research papers that have reported on the machining of PMMA are not available. Among various machining operations, drilling is the most commonly employed machining operation for polymers, such as PMMA, due to the need for mechanical joining [1]. Apart from surface roughness, additional characteristics, of particular importance, such as circularity and cylindricity errors must be considered when optimizing the drilling of polymers $[2,5,12,15]$.

In this study, drilling tests were carried out to experimentally evaluate the hole-quality characteristics (surface roughness, circularity error, and cylindricity error) related to drilling parameters (spindle speed, feed rate, and drill diameter), and the process was first optimized individually for surface roughness, circularity error, and cylindricity error by ANOVA. Because the integrity of the drilled holes is technologically very important, the drilling process was also optimized simultaneously for surface roughness, circularity error and cylindricity error by ANN method.

\section{Materials and methods}

The material used in this study is polymethylmethacrylate (PMMA). Due to its remarkable optical properties, PMMA is one of the most used polymers for optical applications that require drilling operations. Many PMMA engineering components often undergo loading and unloading conditions during their service which may produce significant creep and relaxation phenomenon [23].

\section{Dynamic Mechanical Analysis}

The dynamic mechanical properties of PMMA were measured using a dynamic mechanical analyzer (DMA 242C, Netzsch-Geratebau $\mathrm{GmbH}$ ) in single cantilever bending mode. The DMA tests were performed in the temperature range of 20 to $200^{\circ} \mathrm{C}$, at different frequencies $(0.1,0.316,1,3.16$, and $10 \mathrm{~Hz}$ ). Samples of $10 \times 10 \times 2 \mathrm{~mm}^{3}$ were cut from PMMA plates, which were used for drilling.

\section{Drilling experiments}

The drilling experiments were carried out on a CNC machine with 2.5 axis (Model EMCO MILL 55 CNC, EMCO MAIER Ges. m.b.H. Austria) with SINUMERIK 840D programming code from SIEMENS. The schematic representation of the drilling experiments, including the active zone of the drilling process, is shown in Figure 1. Commercially available drills made of HSS Co (Cobalt steel without coating) with a point angle of $120^{\circ}$ were considered for drilling of $15 \times 60 \times 150 \mathrm{~mm}^{3} \mathrm{PMMA}$ work-pieces (Figure 1).

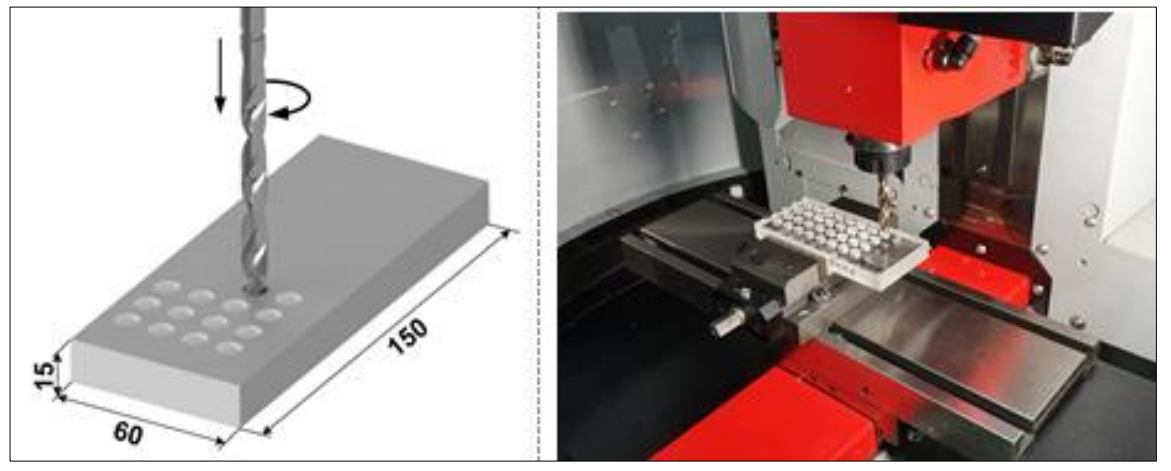

Figure 1. Experimental set-up for drilling experiments 
The drilling experiments, under dry conditions, combine spindle speed, feed rate, and drill diameter (Table 1) generating an experimental plan that is suitable for optimization using both the ANOVA and ANN methods, i.e. a full factorial design with one factor at four levels (feed rate), one factor at three levels (spindle speed) and one factor at two levels (drill diameter), as it is shown in Table 2.

Table 1. Level and coded values for the drilling parameters

\begin{tabular}{|c|c|c|c|c|}
\hline \multirow{2}{*}{ Factors } & \multicolumn{4}{|c|}{ Level } \\
\hline & 1 & 2 & 3 & 4 \\
\hline Drill diameter (mm), D & 8 & 10 & & \\
\hline Spindle speed (rev/ $\mathrm{min}), \mathrm{S}$ & 500 & 1000 & 1250 & \\
\hline Feed rate $(\mathrm{mm} / \mathrm{min}), \mathrm{F}$ & 25 & 50 & 75 & 150 \\
\hline
\end{tabular}

In order to analyze the process repeatability and reproducibility, for each combination of experimental parameters presented in Table 2, four holes were successively drilled. Prior to drilling, centering holes were machined with a $3.2 \mathrm{~mm}$ drill diameter and the surface was inspected for defects or cracks.

Table 2. L24 design for drilling of PMMA

\begin{tabular}{|c|c|c|c|}
\hline $\begin{array}{c}\text { Observation } \\
\text { number }\end{array}$ & $\begin{array}{l}\text { Drill diameter } \\
(\mathrm{mm})\end{array}$ & $\begin{array}{l}\text { Spindle speed } \\
\text { (rev/min) }\end{array}$ & $\begin{array}{l}\text { Feed rate } \\
(\mathrm{mm} / \mathrm{min})\end{array}$ \\
\hline 1 & 1 & 1 & 1 \\
\hline 2 & 1 & 1 & 2 \\
\hline 3 & 1 & 1 & 3 \\
\hline 4 & 1 & 1 & 4 \\
\hline 5 & 1 & 2 & 1 \\
\hline 6 & 1 & 2 & 2 \\
\hline 7 & 1 & 2 & 3 \\
\hline 8 & 1 & 2 & 4 \\
\hline 9 & 1 & 3 & 1 \\
\hline 10 & 1 & 3 & 2 \\
\hline 11 & 1 & 3 & 3 \\
\hline 12 & 1 & 3 & 4 \\
\hline 13 & 2 & 1 & 1 \\
\hline 14 & 2 & 1 & 2 \\
\hline 15 & 2 & 1 & 3 \\
\hline 16 & 2 & 1 & 4 \\
\hline 17 & 2 & 2 & 1 \\
\hline 18 & 2 & 2 & 2 \\
\hline 19 & 2 & 2 & 3 \\
\hline 20 & 2 & 2 & 4 \\
\hline 21 & 2 & 3 & 1 \\
\hline 22 & 2 & 3 & 2 \\
\hline 23 & 2 & 3 & 3 \\
\hline 24 & 2 & 3 & 4 \\
\hline
\end{tabular}

After drilling four holes with the same combination of cutting parameters, the temperature of the drill was measured using a thermal image camera (Flir i7, FLIR SYSTEMS Inc. USA) and, then, the drill was cooled down in ambient temperature until reached the room temperature $\left(23 \pm 1^{\circ} \mathrm{C}\right)$. Additionally, after machining each set of four identical holes, the drill was inspected on an optical microscope for wear.

\section{Measurement of surface quality parameters}

The surface quality of the drilled holes was evaluated in terms of the surface roughness, circularity error, and cylindricity error. The surface roughness was measured with a profilometer (Mitutoyo Surftest 
SJ-210, Japan) equipped with Surftest SJ Communication Tool software. The experimental set-up used for surface roughness measurement of drilled holes is presented in Figure 2. The $R_{a}$ surface roughness was measured as the arithmetic average of the absolute values of effective profile ordinates with respect to median line that is considered as origin [5]. For $R_{a}$, the roughness measurement range of the profilometer is from -200 to +160 microns [24].

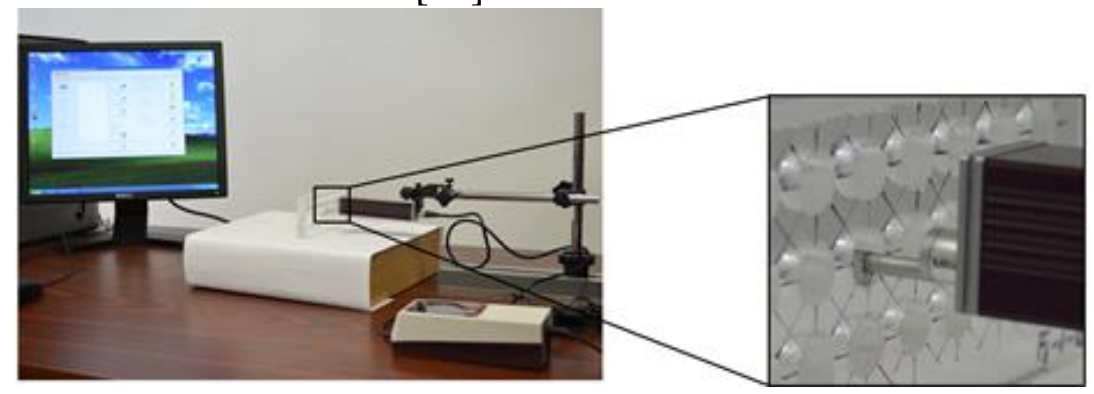

Figure 2. Measurement set-up for surface roughness

The TESA Micro-Hite coordinate measuring machine (MH3D, Tesa, Switzerland) was used to measure the circularity and cylindricity errors. Figure 3 shows the measurement procedure for circularity error (Figure 3a) and cylindricity error (Figure 3b).

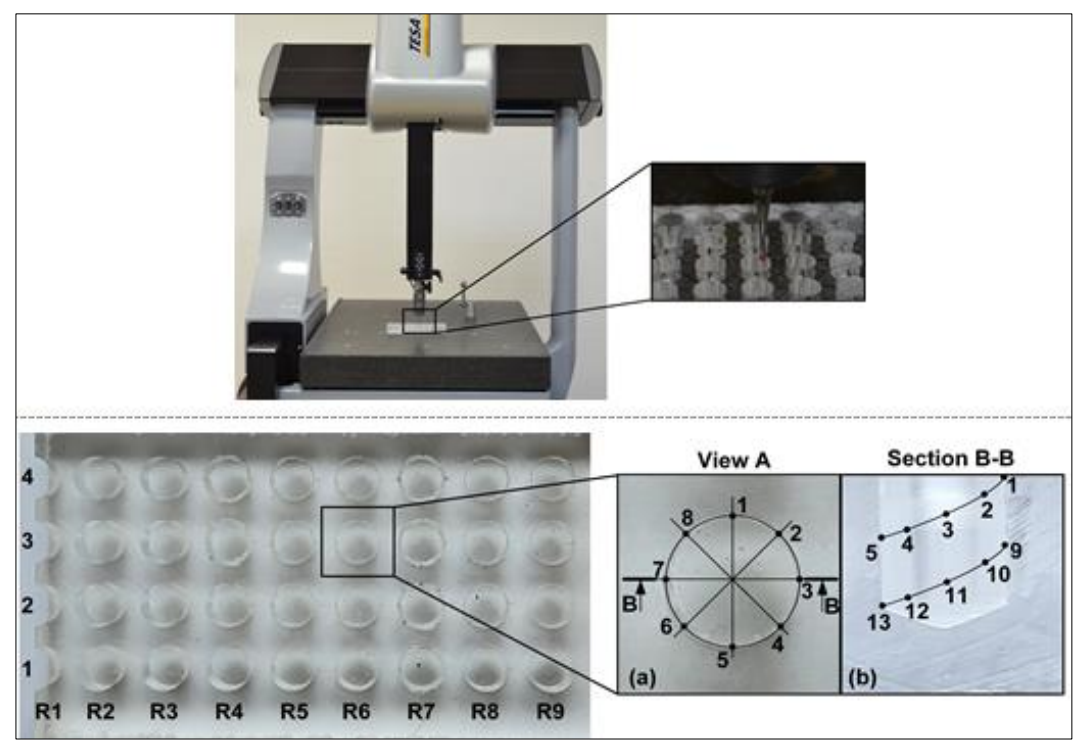

Figure 3. Experimental set-up for circularity and cylindricity errors measurement

As shown in Figure 3a, the circularity error was measured in 8 points at about $1 \mathrm{~mm}$ from the hole entry side, and the average values were considered for the statistical analysis and ANN prediction. The circularity error at the hole entry was evaluated as the maximum distance between the real hole profile $(D)$ and adjacent circle $\left(D_{0}\right)$, as shown in Figure 4. The adjacent circle is the theoretic or programmed drilled hole [5].

For cylindricity error, the measurement trajectory was a spiral from the upper to the lower part of the hole, as shown in Figure 3b. The measurement points for calculating the cylindricity error were obtained as the intersection of the spiral with planes that cut the hole on longitudinal direction in 1-5, 2$6,3-7,4-8$ points. The intersection of the spiral with these planes generates 13 points of measurement along the hole (Figure $3 b$ ).

It should be noted that the minimum number of measurement points required by the machine for calculating the cylindricity error is 10 . The cylindricity error was evaluated as the maximum distance between real surface of the hole $(D)$ and adjacent cylinder to this hole (Figure 4). 


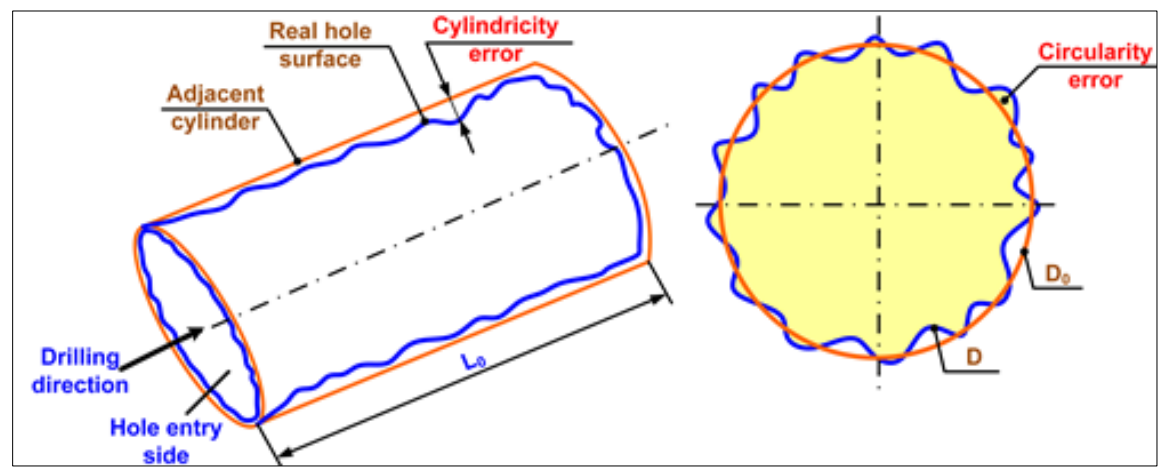

Figure 4. Schematic representation of circularity and cylindricity errors

\section{Analytical modeling \\ Analysis of variance}

The analysis of variance (ANOVA) was used to assess the statistical significance of the drilling parameters (spindle speed, feed rate, and drill diameter) on the surface quality parameters (surface roughness, hole circularity and cylindricity errors) [25]. The P-values less than 0.05 in ANOVA indicates that the effect of the process parameters and/or the corresponding interactions on the response parameters are significant at $95 \%$ confidence level. Main effects plots were also constructed to further support the finding from the analysis of variance. It must be noted that priori to ANOVA, the Anderson-Darling normality test was applied in order to check the normality hypothesis [25].

\section{Architecture and training of the ANN model}

The main goal was to predict the influence of the cutting parameters on the response parameters that characterize the quality of the drilled holes such as surface roughness, circularity and cylindricity errors.

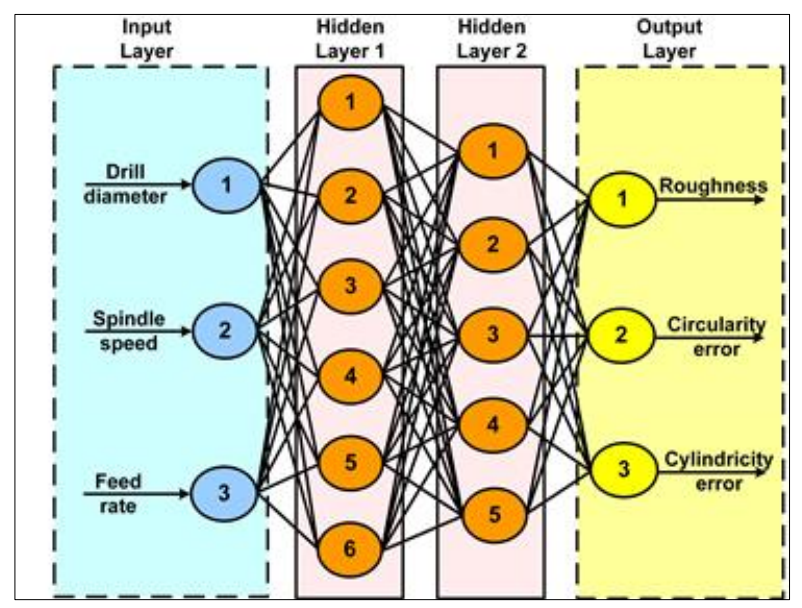

Figure 5. ANN architecture for hole-quality Prediction

Depending on the complexity of mathematical model, which connects the inputs and outputs, the neural network can be designed with one, two or three hidden layers [26], while the number of the neurons in the hidden layers is recommended to be determined based on the trial-and-error method [1922].

A four-layer ANN model was used in this study, as shown in Figure 5. The neural model was generated using a commercial software, EasyNNplus [27] that uses a backpropagation algorithm and a sigmoidal transfer function to build multilayer perceptron neural networks up to three hidden layers [26].

The trial-and-error method was used in order to find the optimum neural network configuration in terms of the number of hidden layers and number of neurons on each hidden layer of the NN model. Out 
of 24 experimental datasets (Table 2), 22 datasets were used for learning the ANN model and 2 datasets (experimental line 7 and 17 in Table 2) were used for validation. It should be noted that the validation experimental lines were randomly chosen by the EasyNNplus software. During the learning stage, for all the pairs in the training data, the error between the actual output and the desired output was calculated and compared with the training error of $10^{-4}$. The training of the NN was considered to be successful when all errors were less than the training error.

To evaluate the predictive capability of the developed ANN model, the experimental data and predicted values were compared in terms of the mean relative error (MRE) defined as:

$$
M R E=\frac{1}{N} \sum_{i=1}^{N}\left|\frac{l_{i, \exp }-l_{i, A N N}}{l_{i, \exp }}\right| \cdot 100[\%],
$$

where $l_{i, \exp }$ and $l_{i, A N N}$ is the measured and ANN predicted values of $i$ experimental data set, respectively, and $N$ is the total number of experimental data sets.

Therefore, the optimum NN configuration consists of an input layer with 3 neurons (each neuron represents a cutting parameter: spindle speed, feed rate and drill diameter), an output layer with 3 neurons (each neuron represents a surface quality parameter: surface roughness, circularity error and cylindricity error) and two hidden layers with 6 neurons on the first hidden layer and 5 neurons on the second hidden layer. This NN configuration (3-6-5-3) results in MRE less than 5\% for the surface roughness and the circularity error, and less than $7 \%$ for the cylindricity error.

\section{Results and discussions \\ Storage modulus and loss factor}

Figure 6 shows the variation of the storage modulus $\left(E^{\prime}\right)$ and the loss factor $(\tan \delta)$ with temperature as a function of frequency. The storage modulus of the PMMA decreased with increasing temperature, and increased with increasing frequency.

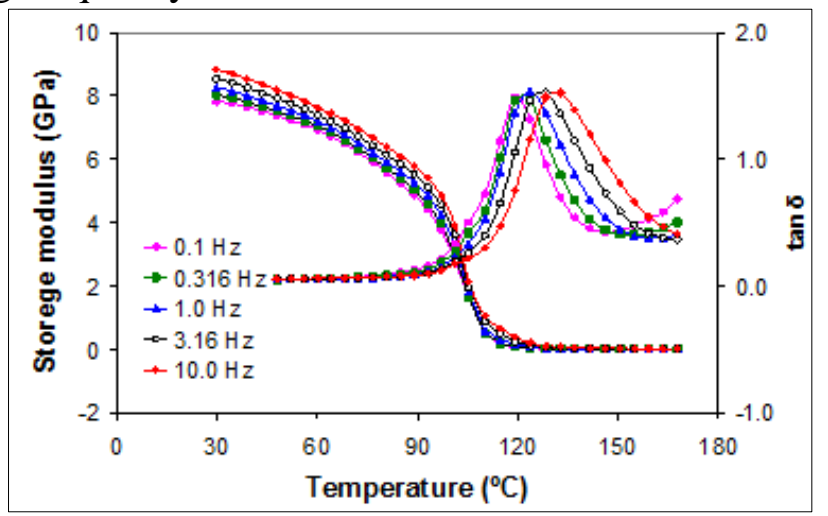

Figure 6. Variation of storage modulus and $\tan \delta$ with temperature as a function of frequency

As it can be seen in Figure 6, the storage modulus decreases sharply in the glass transition region (the inflection point of the storage modulus or the peak of the loss factor) and then remains almost constant at higher temperatures. For example, at $10 \mathrm{~Hz}$, the storage modulus decreased with increasing temperature from about $9 \mathrm{GPa}$ at $30^{\circ} \mathrm{C}$ to about $0.4 \mathrm{GPa}$ at $120^{\circ} \mathrm{C}$, and $0.015 \mathrm{GPa}$ at $165^{\circ} \mathrm{C}$. The sharp drop at the glass transition temperature is attributed to the viscoelastic behavior of the polymer [28]. The $\tan \delta$ curves show a peak corresponding to the glass transition temperature $\left(T_{g}\right)$ of PMMA. From Figure 6, a shift of the $T_{g}$ to higher temperature as the frequency increases (from $119^{\circ} \mathrm{C}$ for $0.1 \mathrm{~Hz}$ to $133^{\circ} \mathrm{C}$ for $10 \mathrm{~Hz}$ ) is clearly observed. Based on these results, it can be concluded that the PMMA will exhibit rubber-like behavior if the temperature in the drilling zone is higher than the glass transition temperature. 

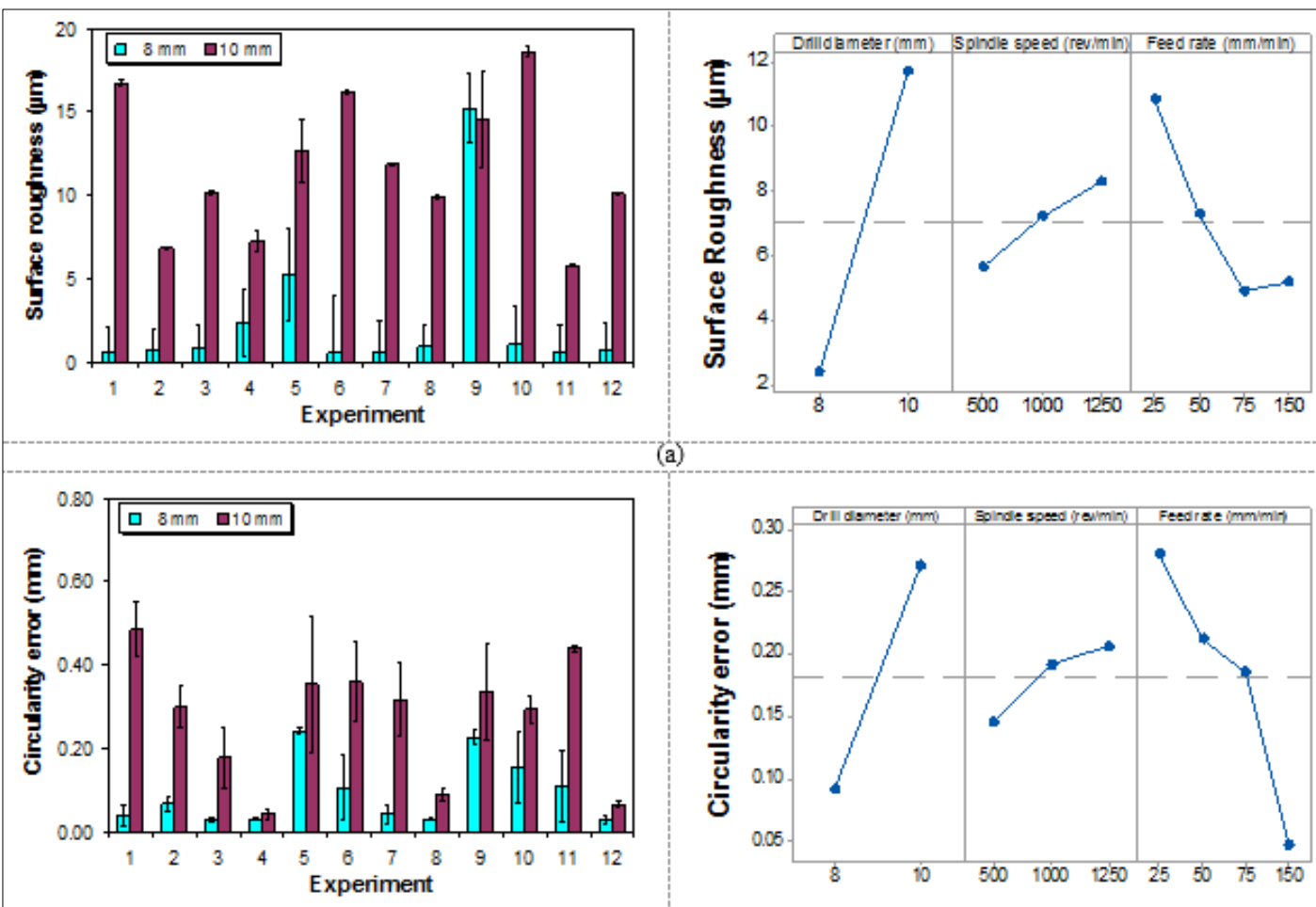

(a)
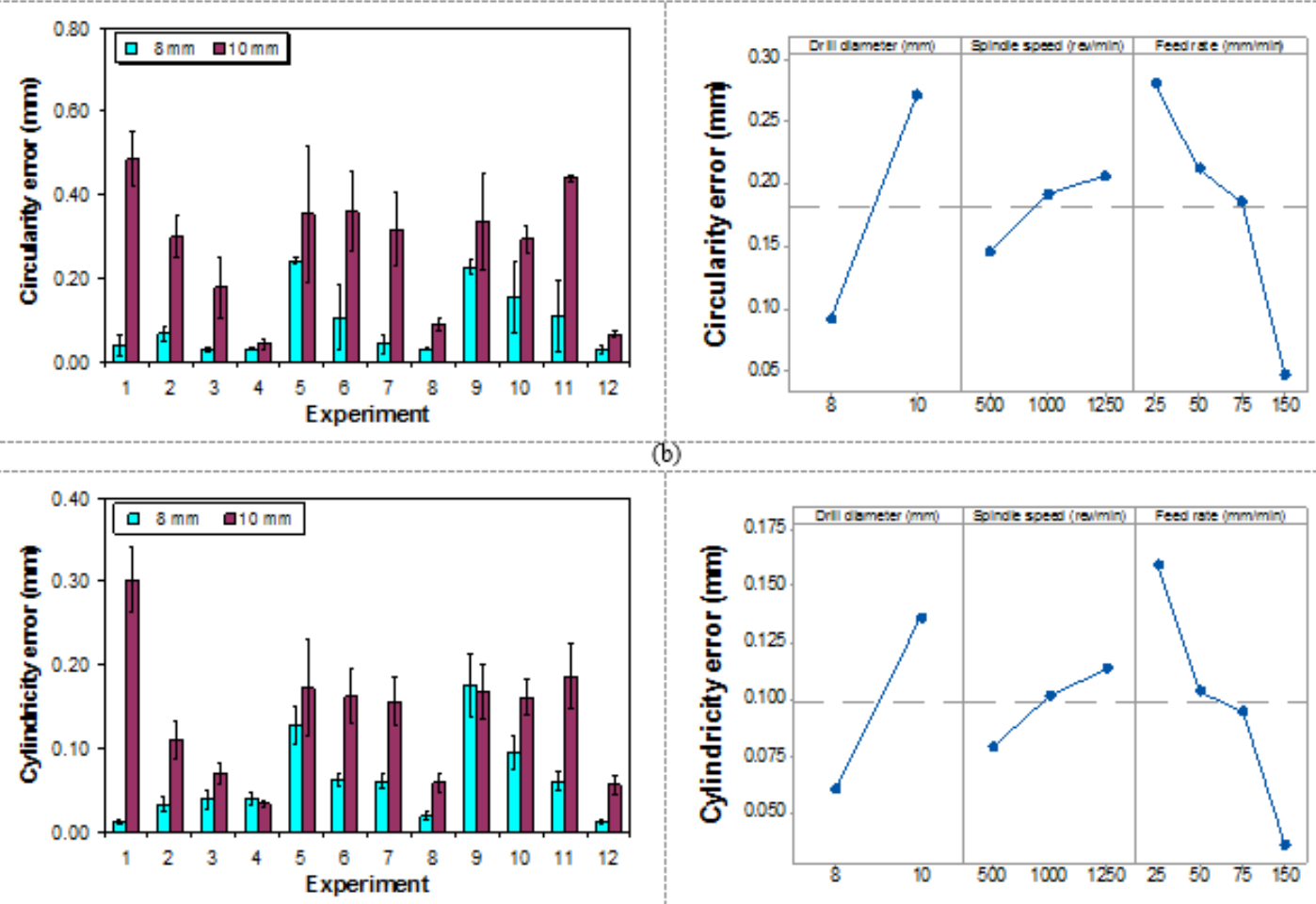

(b)

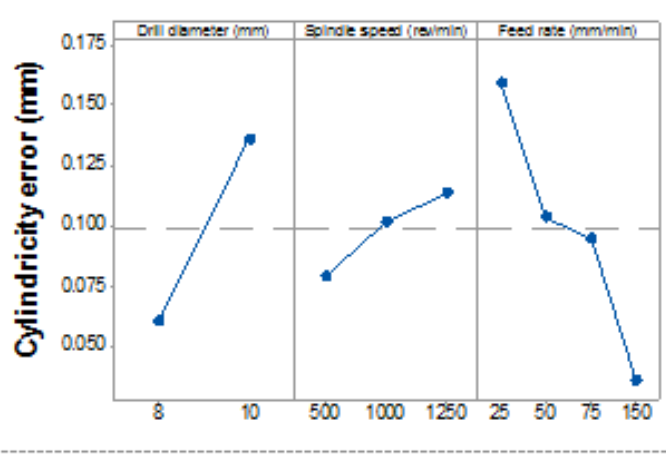

Figure 7. Effect of drilling parameters on the surface quality characteristics:

(a) surface roughness, (b) circularity and (c) cylindricity (average values)

\section{Hole-quality parameters}

Figures $7 \mathrm{a}, 7 \mathrm{~b}$ and $7 \mathrm{c}$ show the variation of the hole-quality parameters with respect to different drilling conditions. The error bars represent the standard deviation of four measurements. As shown in these figures, hole-quality parameters increased with increasing drill diameter and spindle speed, and decreased with increasing feed rate. In other words, the drilling process became more unstable with increasing spindle speed and decreasing feed rate.

The lowest surface quality in terms of surface roughness was obtained for the $10 \mathrm{~mm}$ drill, with $R_{\mathrm{a}}$ values between 6 and $19 \mu \mathrm{m}$ (Figure 7a). On the other hand, appreciable damage (circularity error) was observed at the entry of the holes machined with $10 \mathrm{~mm}$ drill and feed rate of $25 \mathrm{~mm} / \mathrm{min}$, with circularity errors about $0.4 \mathrm{~mm}$.

When drilling with low feed rates and spindle speeds, the friction between the tool and chip increased and, as a consequence, the temperature in the cutting zone increased as well. For example, when drilling with $500 \mathrm{~mm} / \mathrm{rev}$ and $25 \mathrm{~mm} / \mathrm{min}$, the temperature developed in the drill was about $130^{\circ} \mathrm{C}$ after drilling of the 4th hole, which is higher than the $T_{g}$ of the PMMA. Thus, the workpiece and chips were locally melted and adhered to the drill cutting edges, resulting in holes with very rough surface with some 
cratering damage and plastering matrix, as can be seen in Figure 8a. Therefore, it is not recommended to drill the PMMA with low feed rates in combination with low spindle speeds.

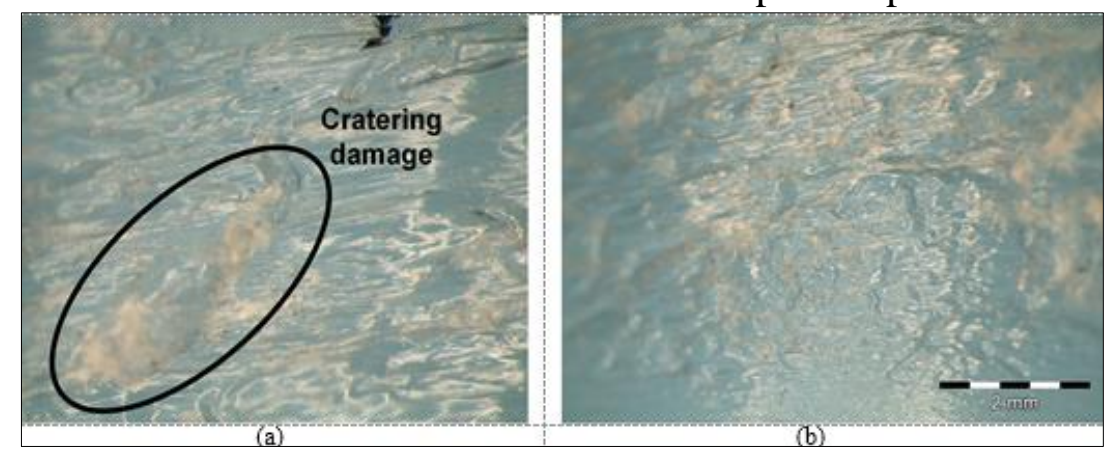

Figure 8. Hole surface when drilling with $25 \mathrm{~mm} / \mathrm{min}, 500 \mathrm{rev} / \mathrm{min}$ and $10 \mathrm{~mm}$ drill diameter (a) 2 nd hole of the row, and (b) 4th hole of the row

At the same time, based on the experimental results, it was found that it is also not recommended to drill under dry conditions more than 3 holes in a row with a combination of low feed rate and low spindle speed. In this particular case, the chip was wrapped on the drill, and when the temperature was high enough, the chips adhered to the hole-surface, resulting in high roughness values (Figure $8 \mathrm{~b}$ ).

For the $8 \mathrm{~mm}$ drill diameter, generally, good results in terms of surface roughness were obtained when using low spindle speed (500 rev/min) and medium feed rates (50 and $75 \mathrm{~mm} / \mathrm{min}$ ). As for the 10 $\mathrm{mm}$ drill diameter, good results in terms of surface roughness were obtained when using low spindle speed (500 rev/min) and higher feed rate $(150 \mathrm{~mm} / \mathrm{min})$.

\section{ANOVA results}

The results of ANOVA for the surface roughness are presented in Table 3. These results show that the effect of the drill diameter is statistically significant with a contribution of $57 \%$, followed by the feed rate with a contribution of about $15 \%$, and the interaction between spindle speed and feed rate with a contribution of about $8 \%$. The other parameters and interactions have a contribution less than $10 \%$ and are not statistically significant. The drill diameter and spindle speed have a negative impact on the surface roughness, while the feed rate has a positive effect up to $75 \mathrm{~mm} / \mathrm{min}$, as shown by the main effects plot in Figure 7a.

The ANOVA results for the circularity are given in Table 4. As can be seen in Table 4, the drill diameter and the feed rate have a statistically significant effect on the circularity with a contribution of 39 and $35 \%$, respectively, whereas the interaction between the drill diameter and feed rate has a contribution of about $9 \%$.

Table 3. Analysis of variance for the surface roughness

\begin{tabular}{|c|c|c|c|c|c|c|}
\hline Source & DF & Seq SS & Adj SS & Adj MS & F & P \\
\hline Drill diameter (mm) & 1 & 516.264 & 516.264 & 516.264 & 26.91 & 0.002 \\
\hline Spindle speed (rev/min) & 2 & 28.126 & 28.126 & 14.063 & 0.73 & 0.519 \\
\hline Feed rate (mm/min) & 3 & 132.858 & 132.858 & 44.286 & 2.31 & 0.176 \\
\hline Drill diameter $\times$ Spindle speed & 2 & 8.958 & 8.958 & 4.479 & 0.23 & 0.799 \\
\hline Drill diameter ×Feed rate & 3 & 30.111 & 30.111 & 10.037 & 0.52 & 0.682 \\
\hline Spindle speed ×Feed rate & 6 & 71.167 & 71.167 & 11.861 & 0.62 & 0.713 \\
\hline Residual Error & 6 & 115.12 & 115.12 & 19.187 & & \\
\hline Total & 23 & 902.604 & & & & \\
\hline
\end{tabular}

The remaining parameters or interactions have a contribution less than $5 \%$ and are not statistically significant. As shown in Figure $7 b$, the feed rate has a positive effect on the circularity error, which decreases with increasing feed rate, while the spindle speed and drill diameter have a negative impact. 
Table 4. Analysis of variance for the circularity error

\begin{tabular}{|c|c|c|c|c|c|c|}
\hline Source & DF & Seq SS & Adj SS & Adj MS & F & P \\
\hline Drill diameter $(\mathrm{mm})$ & 1 & 0.192813 & 0.192813 & 0.192813 & 24.5 & 0.003 \\
\hline Spindle speed (rev/min) & 2 & 0.016053 & 0.016053 & 0.008026 & 1.02 & 0.416 \\
\hline Feed rate $(\mathrm{mm} / \mathrm{min})$ & 3 & 0.171502 & 0.171502 & 0.057167 & 7.26 & 0.02 \\
\hline Drill diameter $\times$ Spindle speed & 2 & 0.003175 & 0.003175 & 0.001588 & 0.2 & 0.823 \\
\hline Drill diameter $\times$ Feed rate & 3 & 0.043074 & 0.043074 & 0.014358 & 1.82 & 0.243 \\
\hline Spindle speed $\times$ Feed rate & 6 & 0.018429 & 0.018429 & 0.003072 & 0.39 & 0.862 \\
\hline Residual Error & 6 & 0.047228 & 0.047228 & 0.007871 & & \\
\hline Total & 23 & 0.492274 & & & & \\
\hline
\end{tabular}

Table 5. Analysis of variance for the cylindricity error

\begin{tabular}{|l|c|c|c|c|c|c|}
\hline Source & DF & Seq SS & Adj SS & Adj MS & F & P \\
\hline Drill diameter (mm) & 1 & 0.033806 & 0.033806 & 0.033806 & 7.48 & 0.034 \\
\hline Spindle speed (rev/min) & 2 & 0.004873 & 0.004873 & 0.002437 & 0.54 & 0.609 \\
\hline Feed rate $(\mathrm{mm} / \mathrm{min})$ & 3 & 0.045695 & 0.045695 & 0.015232 & 3.37 & 0.096 \\
\hline Drill diameter $\times$ Spindle speed & 2 & 0.001755 & 0.001755 & 0.000877 & 0.19 & 0.829 \\
\hline Drill diameter $\times$ Feed rate & 3 & 0.005542 & 0.005542 & 0.001847 & 0.41 & 0.753 \\
\hline Spindle speed $\times$ Feed rate & 6 & 0.004232 & 0.004232 & 0.000705 & 0.16 & 0.98 \\
\hline Residual Error & 6 & 0.027122 & 0.027122 & 0.00452 & & \\
\hline Total & 23 & 0.123026 & & & & \\
\hline
\end{tabular}

The ANOVA results for the cylindricity are given in Table 5. The drill diameter is found to have a statistically significant effect on the cylindricity with a contribution of about $27.5 \%$. Moreover, the feed rate has a contribution of $37 \%$, while the spindle speed and all interactions were found to have a contribution less than 5\%. As shown in Figure 7c, the cylindricity error is negatively impacted by the increase of drill diameter and spindle speed, while the feed rate has a positive effect on the cylindricity error - the cylindricity error decreased with increasing feed rate.

Based on the ANOVA results it can be concluded that, for the surface roughness, the optimum feed rate is $75 \mathrm{~mm} / \mathrm{min}$, while for circularity and cylindricity the optimum feed rate is $150 \mathrm{~mm} / \mathrm{min}$. Moreover, the lower the spindle speed (500 rev/min) the better the quality of the drilled holes.

\section{ANN prediction}

Figure 9 shows the comparison between hole-quality experimental values and the ANN predictions for the training datasets. The relative errors between the experimental and predicted values are also depicted in this figure.

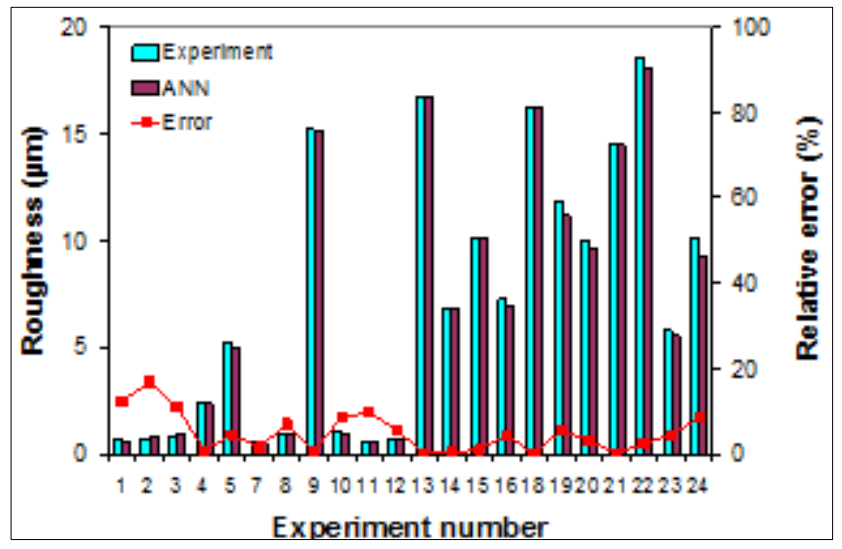




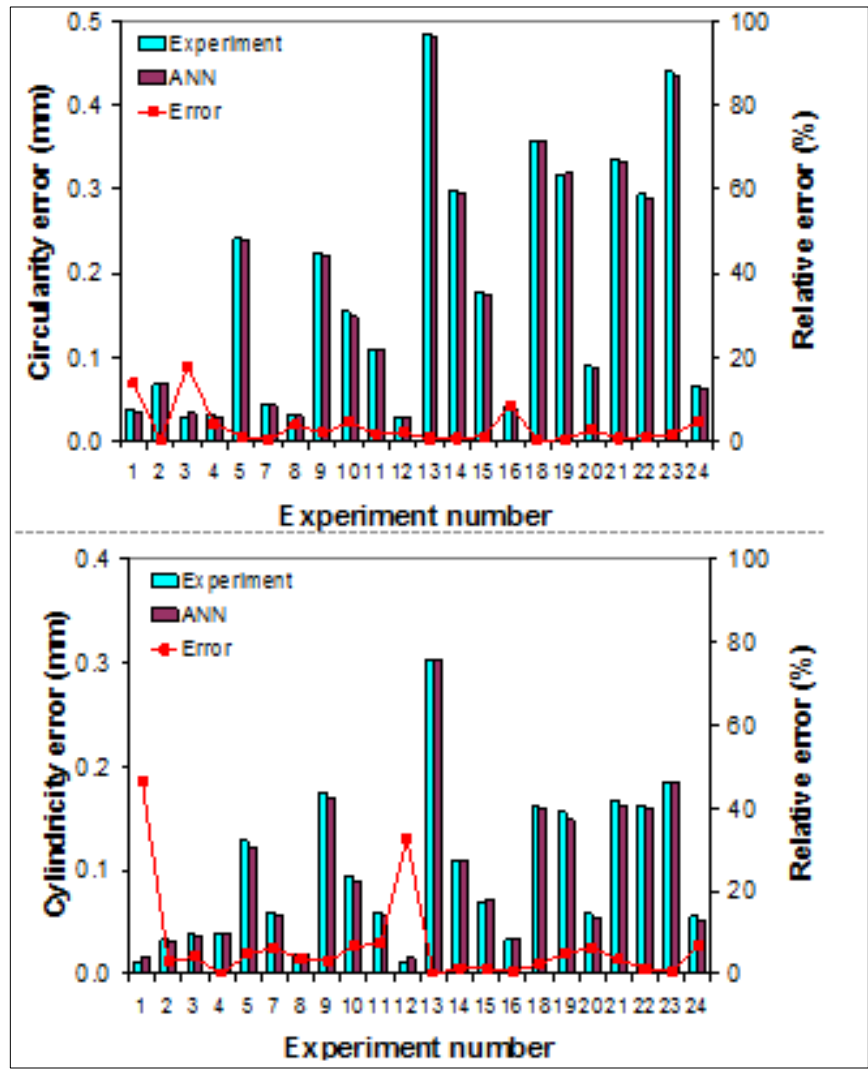

Figure 9. Comparison between experimental values and ANN predictions

As shown in Figure 9, the ANN model generated very good predictions with only few over or under fitted results. The worst prediction was obtained for the experimental line 1 ( $8 \mathrm{~mm}$ drill diameter, 500 $\mathrm{rev} / \mathrm{min}$ spindle speed, and $25 \mathrm{~mm} / \mathrm{min}$ feed rate, in Table 2), with a relative absolute error of $12.20 \%$, $13.85 \%$ and $46.36 \%$ for the surface roughness, circularity error, and cylindricity error, respectively. In this study, the NN output layer had 3 neurons corresponding to the surface roughness, circularity error and cylindricity error, and it was trained simultaneously for all three output neurons. Thus, it is assumed that better prediction may be obtained when only one neuron at the time is considered for the output layer. However, for the surface roughness predicted by the ANN, the absolute mean of the relative errors does not exceed $4.92 \%$, while it reaches $3.39 \%$ and $6.67 \%$ for circularity error and cylindricity error, respectively. Finally, it should be pointed out that the ANN model has a coefficient of correlation very close to unity $(\mathrm{R}=0.999)$.

In order to verify the ANN model, two experimental data sets were randomly selected (experimental line 7 and 17 in Table 2). Table 6 presents the results obtained during the validation tests. It can be seen that the predicted values are very close to the experimental values (measured).

Tables 6. Comparison between measured and ANN validation values

\begin{tabular}{|c|c|c|c|c|c|c|c|c|c|}
\hline \multirow{2}{*}{$\begin{array}{c}\text { Exp. } \\
\text { No. }\end{array}$} & \multicolumn{3}{|c|}{ Surface roughness $(\boldsymbol{\mu m})$} & \multicolumn{3}{c|}{ Circularity error $(\mathrm{mm})$} & \multicolumn{3}{c|}{ Cylindricity error $(\mathrm{mm})$} \\
\cline { 2 - 10 } & Experiment & ANN & \% & Experiment & ANN & \% & Experiment & ANN & $\%$ \\
\hline 7 & 0.522 & 0.530 & 1.48 & 0.043 & 0.043 & 0.47 & 0.060 & 0.056 & 6.17 \\
\hline 17 & 12.664 & 12.593 & 0.56 & 0.353 & 0.354 & 0.20 & 0.172 & 0.165 & 3.90 \\
\hline
\end{tabular}

Tables 6 Comparison between measured and ANN validation values

For the surface roughness and circularity, the relative errors between the experimental and ANN values were found to be below $1.5 \%$, whereas those of the cylindricity vary between 3.90 and $6.17 \%$. In the case of the cylindricity prediction, the higher relative error could be due to the fact that the random 
selection of the datasets for validation might not be representative for the entire series. Anyway, the results obtained clearly show that ANN model is efficient in predicting the hole-quality parameters within the range of variation of the drilling conditions given in Table 2.

\section{Conclusions}

In this study, drilling experiments were conducted on PMMA to assess the impact of drilling parameters (drill diameter, feed rate, and cutting speed) on the hole-quality characteristics (surface roughness, circularity error, and cylindricity error). Analysis of variance (ANOVA) was performed for identifying the process parameters that significantly influence the hole quality characteristics, whereas the artificial neural network (ANN) method was used for predicting the hole quality characteristics. Based on the experimental results and analytical modeling, the following conclusions were drawn:

(i) The quality of the drilled holes decreased with increasing drill diameter and spindle speed, and increased with increasing feed rate. In order to obtain high quality holes, it is recommended drilling with low spindle speed $(500 \mathrm{rev} / \mathrm{min})$ and medium feed rate $(75 \mathrm{~mm} / \mathrm{min})$ for the lower drill diameter $(8 \mathrm{~mm})$, and low spindle speeds (500 rev/min) and high feed rates $(150 \mathrm{~mm} / \mathrm{min})$ for the higher drill diameter $(10$ $\mathrm{mm}$ ). However, based on the ANOVA and the main effects plots, the optimum cutting regime to obtain a compromise between the surface roughness, circularity and cylindricity errors correspond to: 500 $\mathrm{rev} / \mathrm{min}$ spindle speed and $150 \mathrm{~mm} / \mathrm{min}$ feed rate.

(ii) The ANN model was able to accurately predict the hole-quality characteristics with the MRE of the testing data of $4.9 \%$ for surface roughness, $3.4 \%$ for circularity error, and $6.7 \%$ for cylindricity error, which is admissible taking into consideration that the ANN model was trained simultaneously for surface roughness, circularity error and cylindricity error. The validation tests confirm the capability of the ANN model to predict the hole-quality characteristics when drilling the PMMA.

Acknowledgments: This Work Was Supported By The Project "Expert", Financed By The Romanian Ministry Of Research And Innovation In The Framework Of Programme 1 - Development Of The National Research And Development System, Sub-Programme 1.2 - Institutional Performance Projects For Financing Excellence In Research, Development And Innovation, Contract No. $14 \mathrm{pfe} / 17.10 .2018$

This article was presented at Polymer Processing in Engineering Conference - PPE 2019, 7- 9 October 2019, Galati - Romania.

\section{References}

1.PANCHAGNULA, K.K., PALANIYANDI, K., J. Mater. Res. Technol, 7, no. 2, 2018, p. 180;

2.KURT, M., BAGCI, E., KAYNAK, Y., Int. J. Adv. Manuf. Technol., 40, 2009, p. 458;

3.AYKUT, S., Acta Polytech Hungarica, 8, no. 2, 2011, p. 21;

4.VASILE, G., FETECAU, C., SERBAN, A., Mater. Plast., 51, no. 2, 2014, p. 205;

5.SUSAC, F., TABACARU, V., TEODOR, V.G., BAROIU, N., Mater. Plast., 56, no. 1, 2019

6.CAPEllo, E., LANGElla, A., NELE, L., PAOlETti, A., SANTO, L., TAGliAfERRI, V., Machining: Fundamentals and recent advances, Drilling polymeric matrix composites, Springer-Verlag London Limited, J. Paulo Davin, Aveiro, 2008, p. 172;

7.BEATRICE, B.A., KIRUBAKARAN, E., THANGAIAH, P.R.J., WINS, K.L.D., Procedia Eng., 97, 2014, p. 205;

8.GAITONDE, V.N., KARNIK, S.R., CAMPOS RUBIO, J., ABRAO, A.M., CORREIA, A.E., DAVIM, J.P., J. Compos. Mat, 46, 2011, p. 2659;

9.GIASIN, K., GOREY, G., BYRNE, C., SINKE, J., BROUSSEAU, E., Compos. Struct., 212, 2019, p. 159 ;

10.PARK, S. Y., CHOI, W. J., CHOI, C. H., CHOI, S. H., Compos. Struct., 185, 2018, p. 684; 
11.KAVAD, B.V., PANDEY, A.B., TADAVI, M.V., JAKHARIA, H.C., Procedia Technology, 2014, p. 457;

12.VARDHAN, M.V., SANKARAIAH, G., YOHAN, M., Mater. Today: Proceedings, 5, 13, 3, 2018, p. 27058;

13.PRINCY, P., TOMLAL, J.E., JACOB, K.C., PHILIP, K.C., THOMAS, P.C., Polym. Test., 74, 2019, p. 257 ;

14.LIU, D.F., TANG, Y.J., CONG, W.L., Compos. Struct., 94, 2012, p. 1265;

15.VANKANTI, V. K., GANTA, V., J. Mater. Res. Technol., 3, no. 1, 2014, p. 35;

16.HRECHUK, A., BUSHLYA, V., STAHL, J. E., Compos. Struct., 204, 2018, p. 378;

17.FETECAU, C., STAN, F., Measurement, 45, 2012, p. 1367 ;

18.VASILE, G., FETECAU, C., AMARANDEI, D., SERBAN, A., Mater. Plast., 53, no. 1, 2016;

19.JIA, J., DAVALOS, J.F., Compos. Struct., 74, 2006, p. 106;

20.STAMOPOULOS, A.G., TSERPES, K.I., DENTSORAS, A.J., Compos. Struct., 192, 2018, p. 327;

21.CHEN, G., WNAG, H., BEZOLD, A., BROECKMANN, C., WEICHERT, D., ZHANG, L., Compos. Struct., 223, 2019, p. 110951;

22.LOPES, P.A.M., GOMES, H.M., AWRUCH, A.M., Compos. Struct., 92, 2010, p. 1603;

23.STAN, F., FETECĂU, C., STANCIU, N.V., Proceedings of MSEC, ASME, 2, 2017, p. V002T03A017;

24.***Mitutoyo SURFTEST SJ-210, Surface Roughness Measuring Tester SJ-210, User's Manual; 25.MONGOMERY, D. C., Design and analysis of experiments, $7^{\text {th }}$ Edition, John Wiley \& Sons, 2009; 26.AKAMINE, A., DA SILVA, A.N.R., Recent advances in design and decision support systems, An evaluation of neural special interaction models based on a practical application, Kluwec Academic Publishers, Jos P. van Leeuwen \& Harry J. P. Timmermans, Dordrecht, 2004, p. 26;

27.*** EasyNNplus software; Available online: www.easynn.com (accessed on: 10 July 2019);

28.INDRA, R.M., SRINIVASA, R.V., Int. J. Eng. Res. Technol.,3, no. 9, 2014, p. 410.

$\overline{\text { Manuscript received: } 6.02 .2020}$ 